\title{
The Impact of Blockchain Technology on International Trade and Financial Business
}

\author{
Slatvinska Valeria ${ }^{1, *}$, Demchenko Vitaliia ${ }^{2}$, Tretiak Kateryna ${ }^{2}$, Hnatyuk Rostyslav ${ }^{3}$, Yarema Oleg $^{3}$ \\ ${ }^{1}$ Department of Criminal Law, Process and Criminalistics, International Humanitarian University, Odessa, Ukraine \\ ${ }^{2}$ Department of Banking and Insurance, Kyiv National Economic University named after Vadym Hetman, Ukraine \\ ${ }^{3}$ Department of Analytical and International Economics, Faculty of Economics, Ivan Franko National University of Lviv, Ukraine
}

Received October 8, 2021; Revised November 17, 2021; Accepted December 23, 2021

\section{Cite This Paper in the following Citation Styles}

(a): [1] Slatvinska Valeria, Demchenko Vitaliia, Tretiak Kateryna, Hnatyuk Rostyslav, Yarema Oleg , "The Impact of Blockchain Technology on International Trade and Financial Business," Universal Journal of Accounting and Finance, Vol. 10, No. 1, pp. 102-112, 2022. DOI: 10.13189/ujaf.2022.100111.

(b): Slatvinska Valeria, Demchenko Vitaliia, Tretiak Kateryna, Hnatyuk Rostyslav, Yarema Oleg (2022). The Impact of Blockchain Technology on International Trade and Financial Business. Universal Journal of Accounting and Finance, 10(1), 102-112. DOI: 10.13189/ujaf.2022.100111.

Copyright $(2022$ by authors, all rights reserved. Authors agree that this article remains permanently open access under the terms of the Creative Commons Attribution License 4.0 International License

\begin{abstract}
This article examines the impact of blockchain technology in the financial sector and international trade. The aim of the article is to measure the effect of blockchain technology on international trade and financial business. The paper uses methods of analysis and synthesis of information from researched academic articles, government programs, reports, and statistical data. The averages and regression analysis (in particular, the calculation of the Pearson coefficient) are used for getting analytical results. Graphic methods are used to summarize the information and to present the understudy materials. According to the results of the study, it can be concluded that blockchain technology has great potential for the development of international trade and financial business. It is possible by improving the settlement of international trade, applying smart contracts in the formation of the transaction, improving logistics chains, and reducing the speed of information and delivery processing, increasing the economic turnover. Blockchain has a positive impact on reducing costs for merchants and the banking sector, predicted by 2030 to decrease costs by $11 \%$ using this technology. The technology will have a very significant impact on the development of intellectual property, which could be particularly activated by the possibility of reducing the impact of pirated copying. It is possible to reduce corruption and fraud by applying blockchain technology in public procurement, which currently accounts for the bulk of international trade. Blockchain
\end{abstract}

technology will add $\$ 3$ trillion in additional business value by 2030 and $\$ 866$ bln in international trade, including financial business.

Keywords Blockchain, Cryptocurrency, Smart-Contract, International Trade, Financial Business, Intellectual Property

\section{Introduction}

International trade and financial business are essential components of the global economy. These activities involve the movement of goods across borders, which is always accompanied by a large amount of documentation, settlement, long-term customs operations, which negatively affect delivery times and prevent the formation of efficient supply chains.

Blockchain technology was recently associated with cryptocurrencies, but today it is also actively used outside the financial sector. In particular, it makes it possible to form, store and dispose of data efficiently in flexible ways of using it and ensuring full security of these processes. The World Trade Organization (2021) now believes that blockchain is one of the most effective rapidly developing international trade methods. This prediction is based on 
the fact that the technology is already being used to manage assets, accelerate payments and create effective transaction control systems. But blockchain, with all its benefits, is not a panacea for growing economies. Implementing the technology in commercial and, even more, in government organizations is a long-term, expensive procedure requiring staff training to manage trade and business processes effectively. The security problems are also not completely closed, as they can appear at the stage of recording information to the blockchain, which leaves the human factor in the information management.

All predictions in this study are based on the assumption that the business and financial sector will find sufficient financial, labor, and time resources to involve these technologies in their processes. If such organizations have no willingness, or if the technology will be compromised or devalued soon, the predictions will not come true.

\section{Literature Overview}

Blockchain is a research field for many scientists in many different areas, ranging from technical to governmental. At the initial stage of the technology's formation, a large amount of research revealed the essence and potential of the technology.

According to World Trade Organization (WOT) experts, blockchain has a revolutionary impact on international trade and financial business development (Derindag et al., 2021; Sirimanne \& Freire, 2021). That is not surprising since technology has a very rapid evolution. Just a few years ago, it was created for a cryptocurrency operation, but today it goes beyond cryptocurrency management. At the same time, the only way for the formation of its distribution directions is the coverage of all activity spheres. The technology will spread to related sectors with cryptocurrency - international trade and financial business, because its primary goal is to improve mutual settlements and business relations.

According to the World Trade Organization, about 80\% of all international trade financial flows are conducted using traditional forms of financing (Sirimanne \& Freire, 2021). Blockchain could improve the financing process, making it faster, more reliable, and more accessible to all. Many banking organizations already understand these benefits, and are using the technology to improve the quality of their services. Today, according to a survey of financial institutions, most banking institutions have already moved to DLT technology (Derindag et al.,2020). Smart contracts are particularly important in the application of blockchain technology. A smart contract is a type of agreement in the form of coded mathematical algorithms; signing, changing, execution, and termination are possible only with the use of computer programs
(Blockchain platforms) within the Internet (Nanayakkara et al., 2021). The study of smart contracts is given a lot of attention by researchers, as a result, today we can confidently say that smart contracts can be used in almost all sectors of the economy. The information transfer process uses cryptographic techniques, with peer-to-peer networks that limit control to one side. Such technologies allow producers, suppliers, customers, and other stakeholders to receive complete information without delay (Chang et al.,2019). According to Juniper Research (Smith, 2021), the biggest savings will be felt by those banking structures that deal with cash transactions and compliance. For example, the latter would be able to halve the cost of money-laundering inspections. Blockchain is also a promising technology for the seller of digital content. With the use of technology, the process of monitoring and licensing intellectual property products can be simplified. The use of smart contracts can simplify the process of payment for using products, which is especially relevant for the music industry (Patrickson, 2021).

Beyond these, several studies on the impact of blockchain on international trade (Zhai \& Tan, 2021; Derindag et al., 2020) reveal the general benefits of technology in managing international business processes. However, there are not enough detailed studies and measurements of blockchain's potential for international trade and financial business development, which forms the purpose of the study.

The purpose of the study is to measure the effects of blockchain technology in international trade and financial business.

\section{Methodology}

In order to study the impact of blockchain on international trade and financial business, general scientific methods of analysis, synthesis of information are used. In order to conduct empirical research, statistical data from organizations such as the World Trade Organization, the European Commission, as well as the results of surveys and research companies Gartner, Bloomchain, Juniper, Statista, etc., were investigated. As a result, the blockchain impact on international trade in monetary terms was obtained by comparing and calculating averages, trend, and correlation analysis. The information was collected according to the results, which were further subjected to systematization, grouping, presentation, and forecasting using graphical methods.

\section{Research results}

The cryptocurrency market is rapidly developing. Speaking about the financial sector, it should be noted that in 2020, the cryptocurrency market turnover amounted to 
$\$ 0.84$ billion. Already in 2021 , the indicator will be $\$ 1.46$ billion (Statista, 2021), and further dynamics will develop rapidly, increasing last year's figures almost twofold (Fig. 1.).
However, today, talking about the geographical spread of the technology, blockchain is mostly used in the U.S. (expected turnover of $\$ 4.2$ billion in 2022) and in Western Europe (with $\$ 2.9$ billion) (Figure 2).

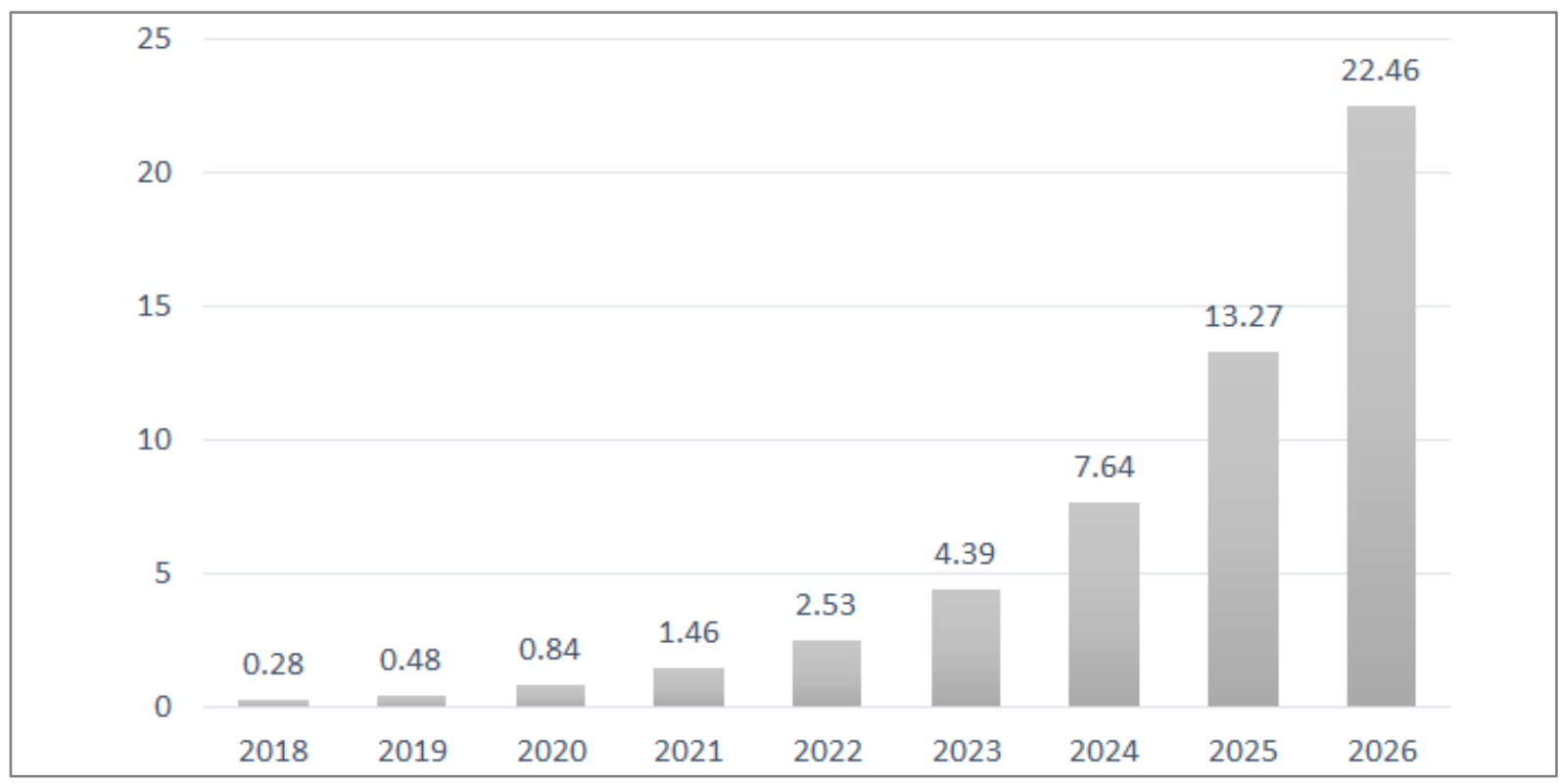

Source: Statista, 2021

Figure 1. Forecast for blockchain technology in the financial industry, $\$$ billion

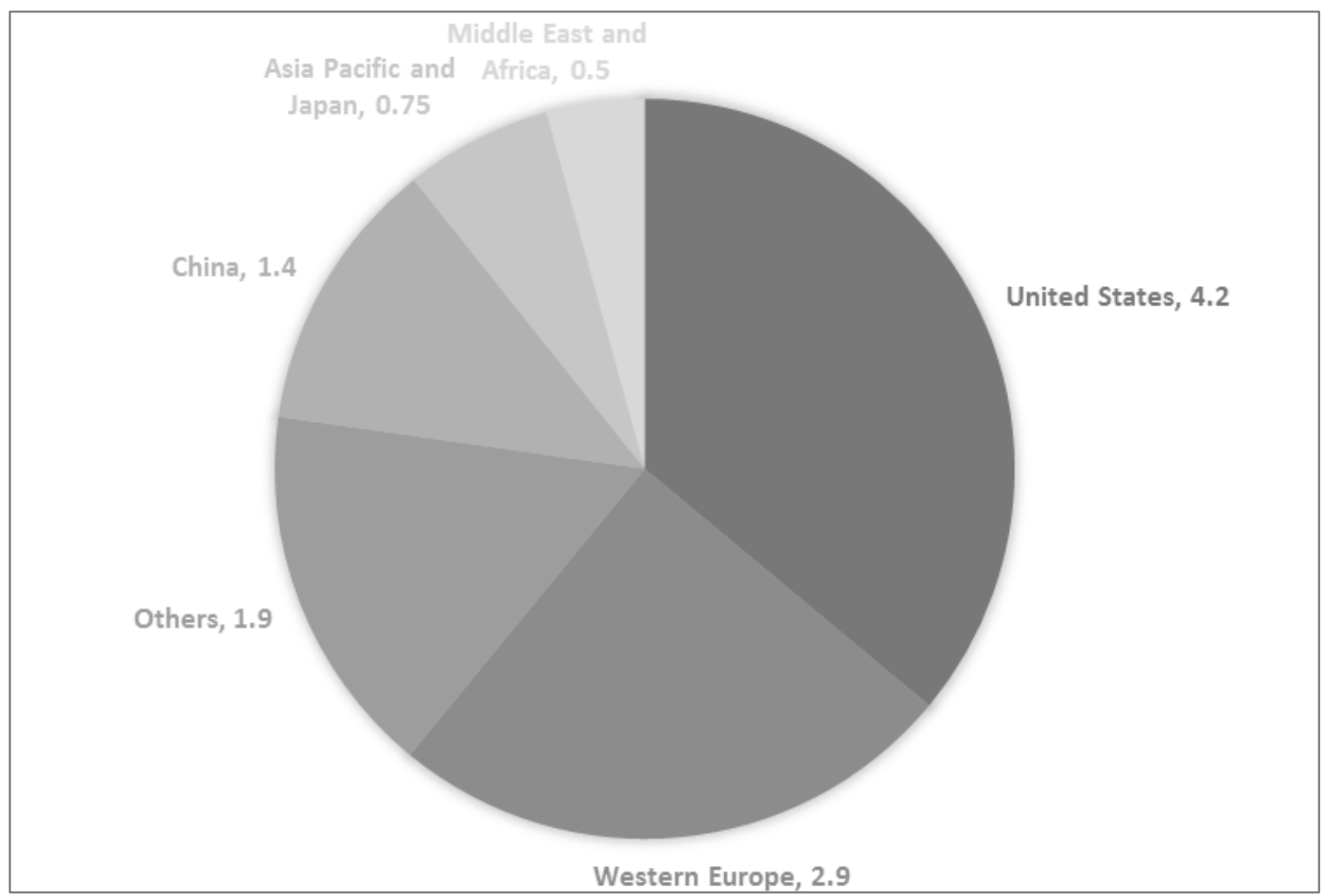

Source: Finances Online, 2021

Figure 2. Forecast of the geographic pattern of blockchain technology used by 2020 
Today, the technology is mostly used to organize cryptocurrency circulation, but with new protocols, blockchain has begun to provide data access and information exchange, protect identity, provide payments, track transactions, etc. (Figure 3.)

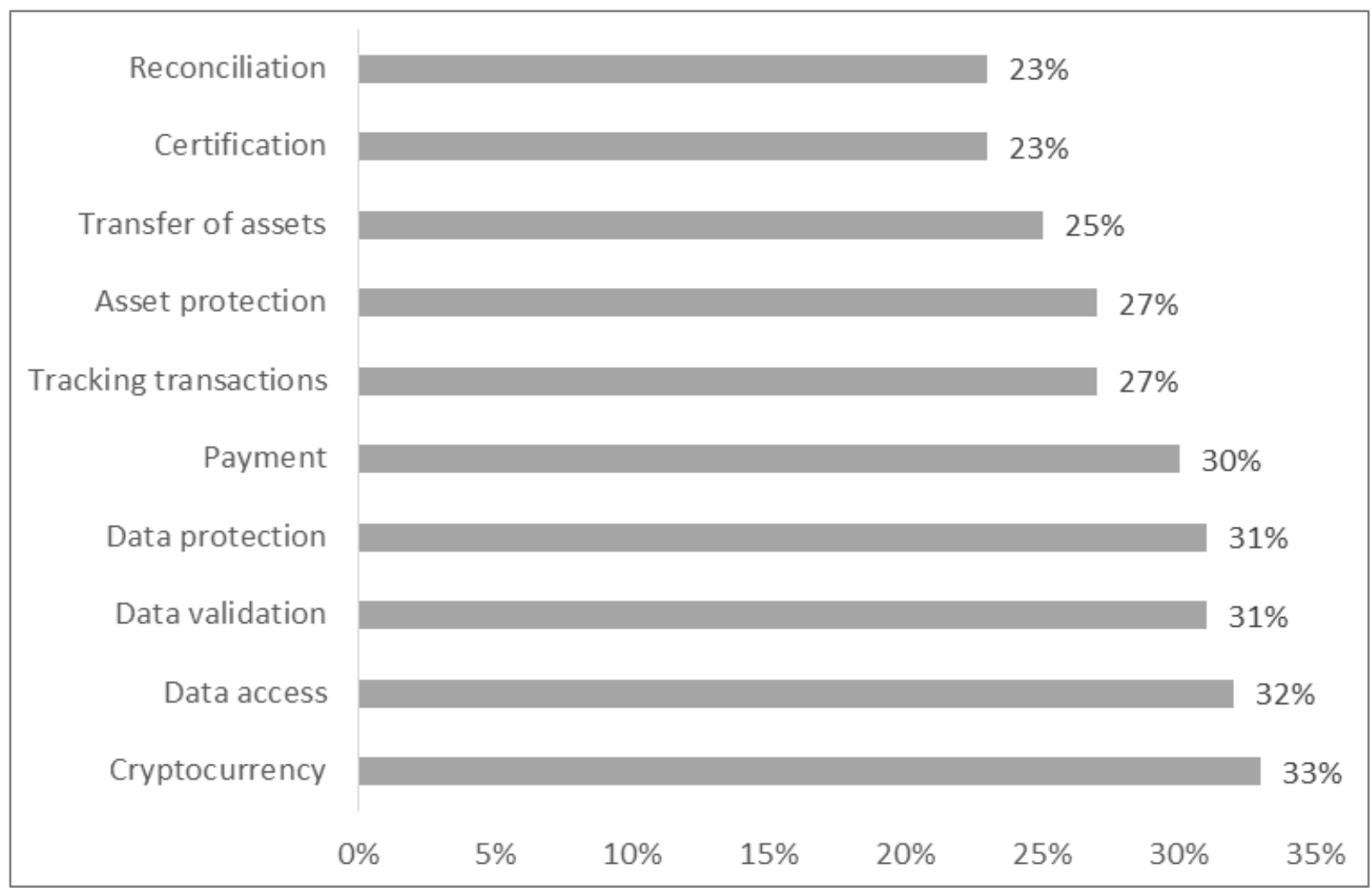

Source: Finances Online, 2021

Figure 3. The main goals of blockchain technology application

We can conclude that the main functions of the technology are to organize mutual settlements, provide information flows, and protect data. Therefore, such innovations are quite in demand in international trade and financial business, especially in a pandemic, during which logistics flows were most affected (Fig.4).

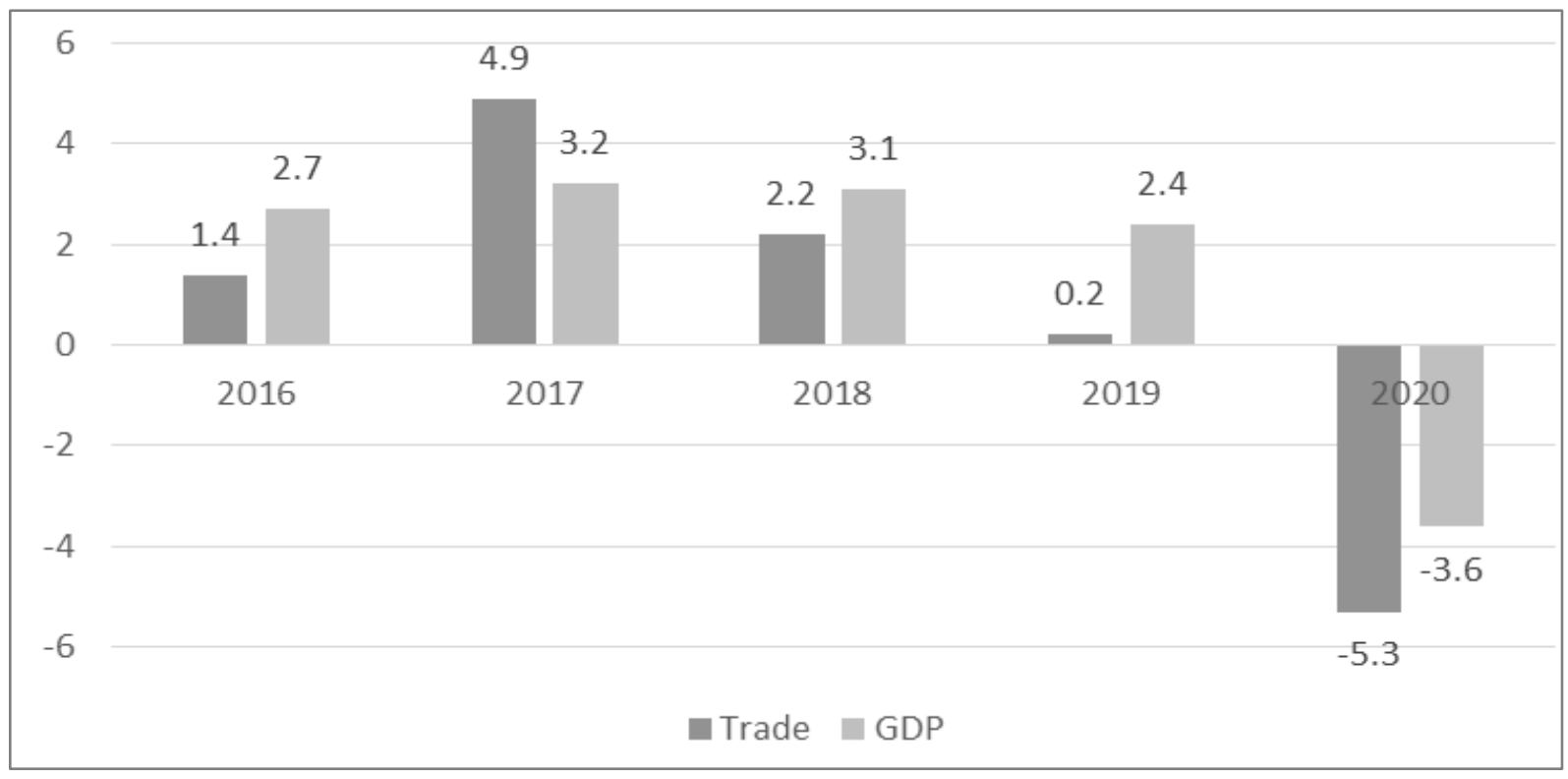

Source: WTO, 2021

Figure 4. Annual growth of international trade and GDP indicators for 2016-2020, \% 


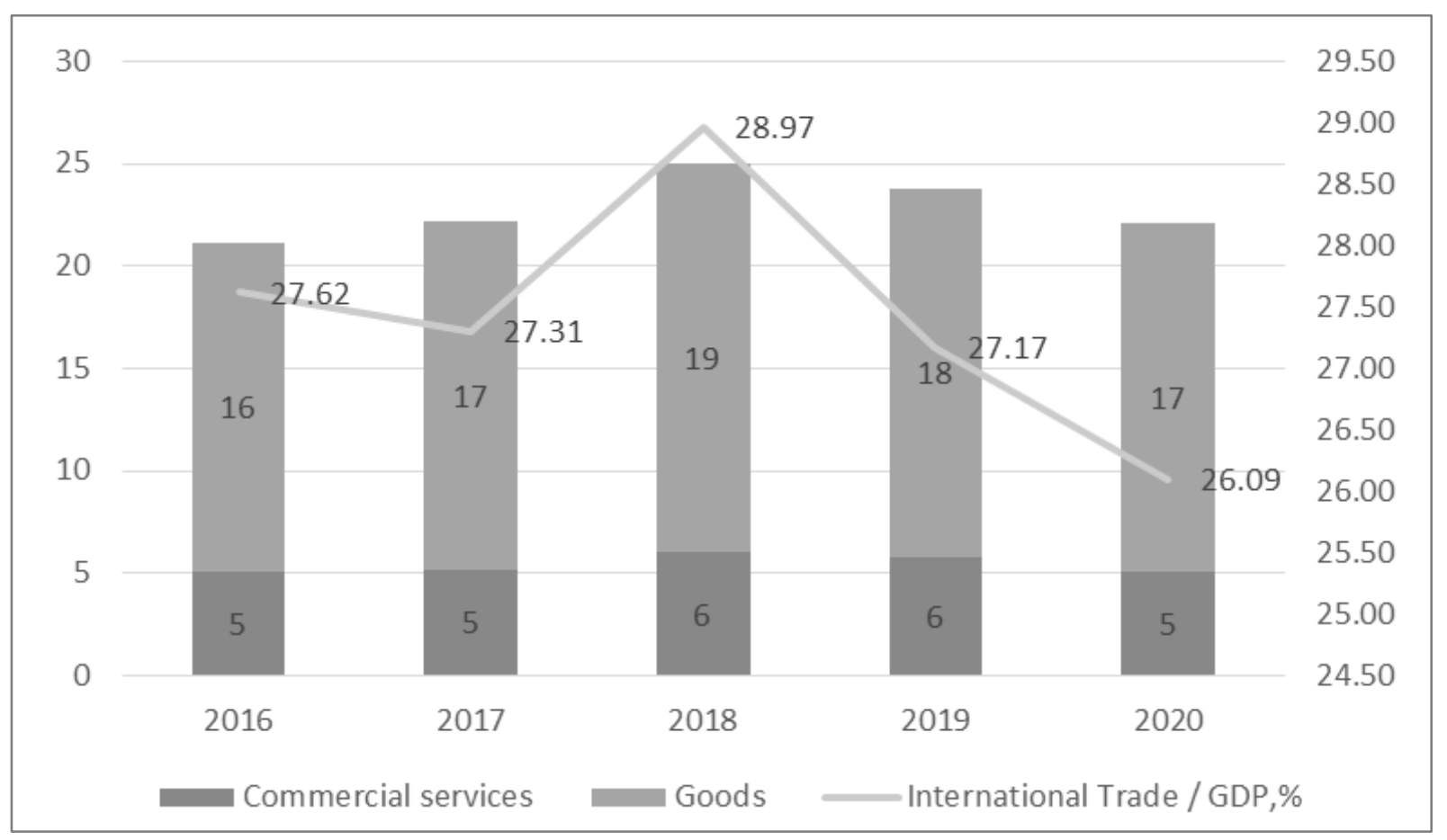

Source: WTO, 2021

Figure 5. Dynamics and structure of international trade 2016-2020 ( $\$$ trillion) and their relation to GDP dynamics

In 2020, international trade activity declined by $5.3 \%$ comparing 2019. At the same time, GDP decreased by $3.6 \%$ for the year, indicating that overall trade suffered more than the general economic processes in the world. It should be noted that international trade accounts for $26 \%$ of GDP as of 2020 , while in 2019 , the international trade to GDP ratio was $27.6 \%$.

Despite the overall negative dynamics of global services, the financial industry has shown a growth of $4 \%$ in 2020. In addition, the activity of the computer industry has also increased (the growth in 2020 is $8 \%$ ).

According to the WTO report (2021), we can talk about the potential of the financial and computer industries, the development of which can compensate for the overall decline in economic activity during the pandemic. In the opinion of the writing team, one of the important tools for the development of data and other industries can be considered a blockchain.

Let us consider the main benefits of applying blockchain technology to international trade and finance.

Improving the settlement of international trade. The use of letters of credit is one of the most common methods of arranging settlements, although recently, there has been a growing trend towards using open accounts. However, traditional financing systems come with additional costs (up to $1 \%$ of the transaction), which become cumbersome for many companies and do not allow for more dynamic development. On the other hand, using open accounts makes supplies riskier; they have to base their cooperation on trust, with no means, tools, and ways to prevent fraud.
Such shortcomings have forced IT and financial startups to reconsider the potential of blockchain technology to simplify the financing process. As the procedure is simplified and the price of money flows decreases, the level of security of such transfers increases, especially when it comes to organizing permanent and long-term business relationships.

In addition, the organization of financial settlements using traditional payment methods creates an additional documentary burden. Transactions with letters of credit require the creation of additional documents, in the process of conducting such operations involves at least a dozen employees of banking institutions. Many institutions simplify these operations by digitizing documents in pdf format, but it also creates additional problems. Blockchain works on transparent terms, and therefore it helps automate processes, increasing the efficiency of transactions and the level of security behind them. Banks' transition to blockchain has been gradual, as they have required adaptation of current automation systems to new technological processes.

Smart contract. The terms of a smart contract are first stated as an agreement on the terms of the contract. Then they are laid out in the form of program code, which is designed to receive certain data, process it according to pre-defined logic, and issue new information based on the processing results, including in the form of commands that are executed automatically. The blockchain network consists of equal participants, providing the power of their computing systems that implement the execution of the 
algorithms on which the functioning of the network is based. Every carried out in the blockchain network operation is verified using complex mathematical calculations. If the majority of all network participants confirm that the operation is true and corresponds to the real state of affairs, it is recorded in the blockchain.

One of the attributes of a smart contract is its autonomy - a technologically developed decentralized system in which all the smart contract conditions are executed automatically, without human intervention. That is, any contract condition must be possible to execute within the system, and other actors have no ability to prevent such execution (Mamchur \& Nedybaliuk, 2018). Autonomy manifests itself as direct (a smart contract in the form of a program collects data, analyzes, and as a result, produces new data and commands). None of the participants in the network, none of the parties to the contract can individually influence the execution of the smart contract.

Improving the supply chain. Blockchain has many applications and can be used in any exchange, agreement, or contract, tracking and making payment. It turns out that blockchain can increase the efficiency and transparency of supply chains and positively affect everything from the warehousing of delivery to payment. The technology ensures consensus: There is no conflict in the transaction chain because all entities in the chain have the same version of the ledger. Everyone on the blockchain network can see the sequence of ownership of an asset within the blockchain. Furthermore, blockchain records cannot be erased, which is critical for implementing supply chain transparency (Figure 6).

Blockchain technology can provide greater visibility into supply chains, as well as lower associated costs and risks. Specifically, adopting blockchain innovation can provide the following key benefits.

- increased monitoring of the supply of materials within the supply chain, which will help in ensuring compliance with the standards set in the company;

- reduced losses associated with illegal or "gray" products;

- increased transparency and compliance when dealing with third-party contract manufacturers;

- reduced documentation and administrative costs.

- Blockchain technology can drive increased transparency in supply chains, reducing the risk of fraud on high-value goods such as diamonds or pharmaceuticals. Blockchain can help companies understand how individual components and finished goods pass through each subcontractor, reduce revenue losses due to counterfeit and gray goods, and increase end-user confidence by reducing or eliminating the negative consequences associated with counterfeit products.

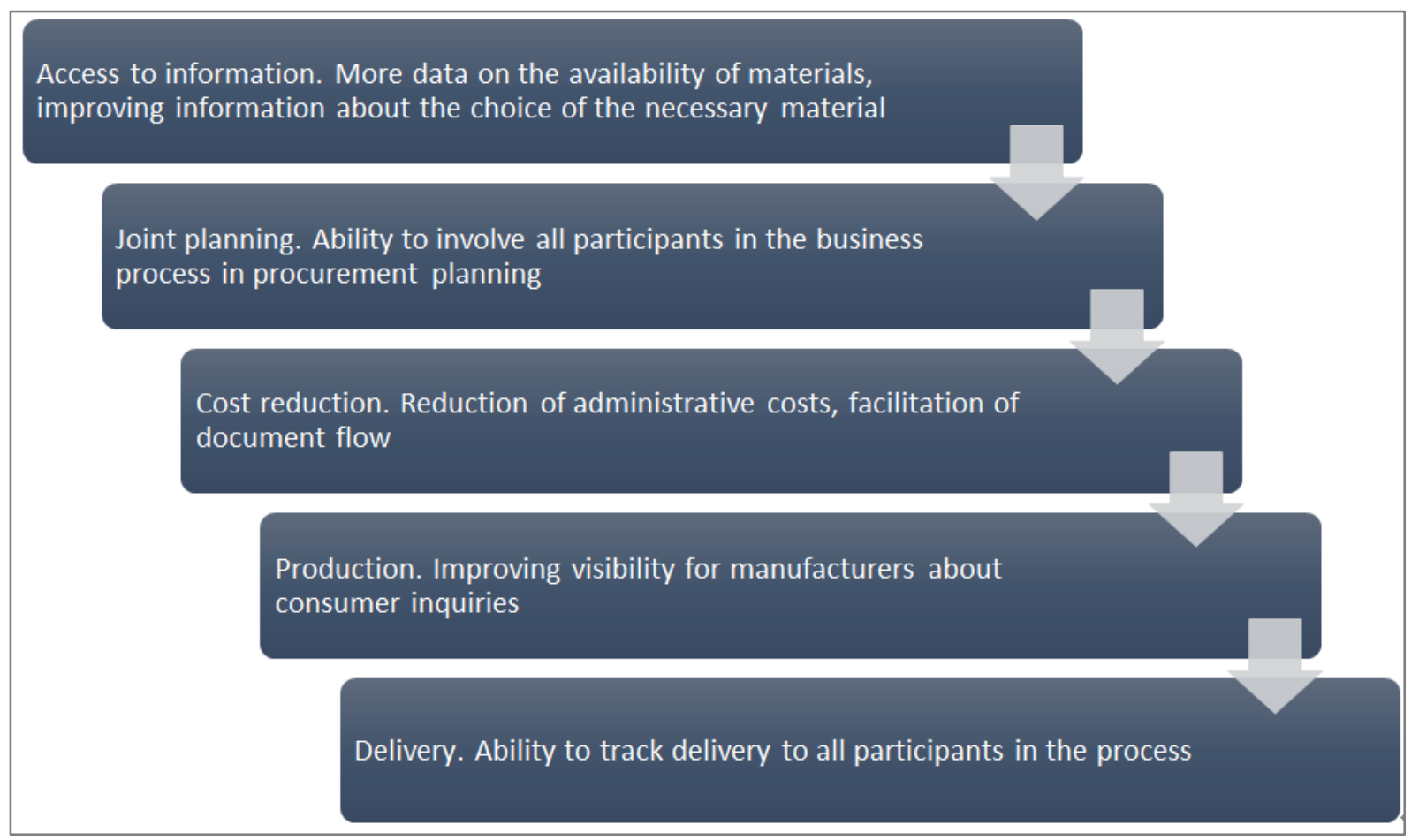

Source: VC, 2021

Figure 6. Improving the supply chain with blockchain technology 


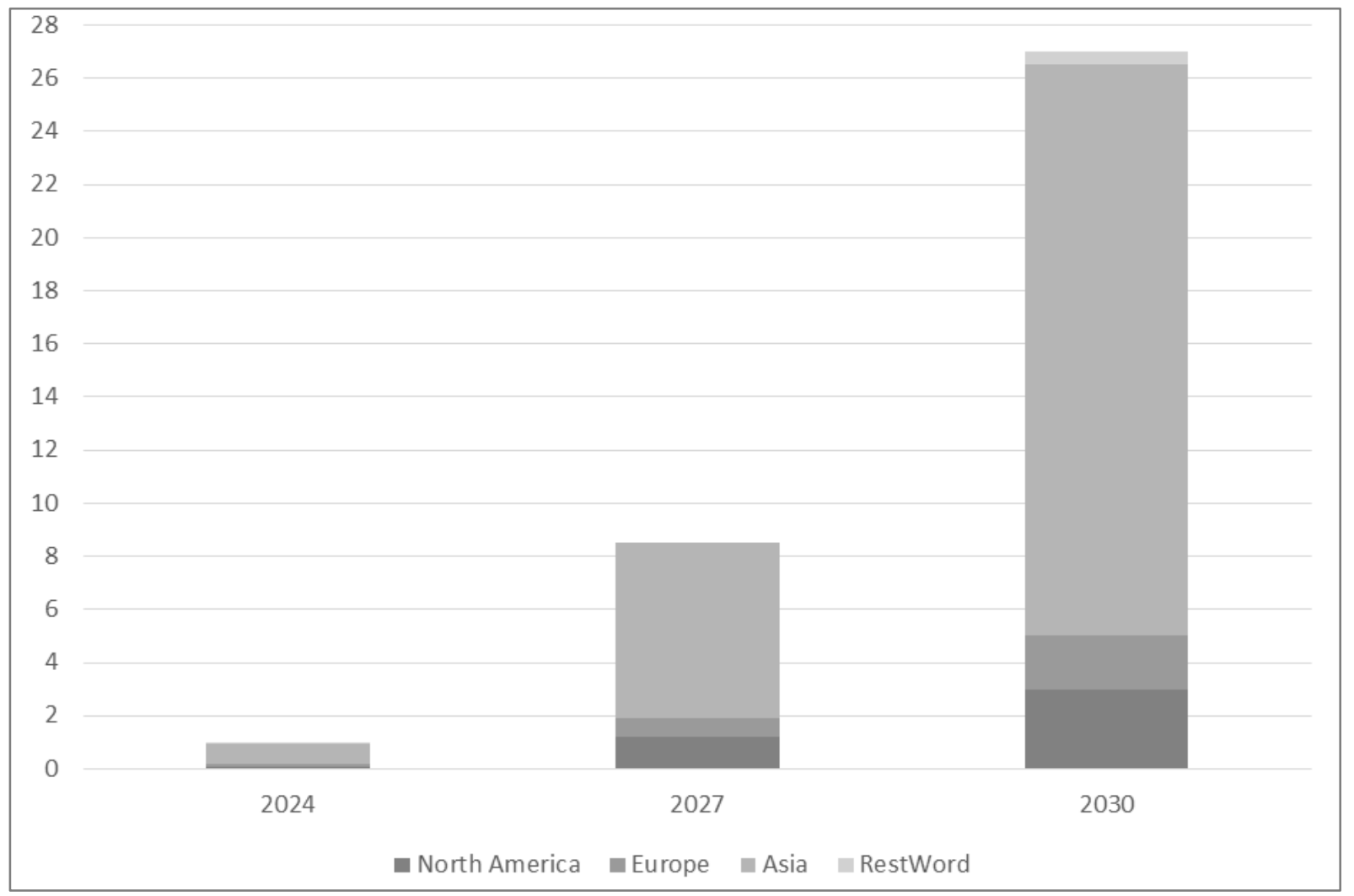

Source: Bloomchain, 2021.

Figure 7. Bank's blockchain implementation costs, $\$$ billion. USD

Reduce intermediation costs. The use of blockchain can reduce the cost of organizing trading activities by automating financial intermediation and coordinating the company's work. In addition, given the fact that quite a large part of the logistics process will be automated, it will also have a significant impact on labor efficiency, optimizing the use of different technologies.

By 2030, financial institutions around the world will save more than $\$ 27$ billion annually in cross-border settlement transactions using blockchain technology. This is the conclusion reached by analysts of Juniper Research (Smith, 2021). Furthermore, as noted in the study, the introduction of blockchain-based solutions will reduce banks' costs by $11 \%$ (Figure 7).

Experts, however, warn that there is no point in expecting rapid cost reductions. Initially, existing methods of checking will be implemented in parallel with methods developed on the blockchain, so it will take several years for all of them to be brought into a single format.

Juniper Research predicts annual cost savings of $\$ 1$ billion by 2024 alone.

The authors believe that in addition to banks, companies involved in food exports will also benefit from blockchain. Within 12 years, they will be able to halve their costs to combat fraudulent activity roughly.

Earlier, global information provider IHS Markit predicted that the value of businesses that use solutions based on distributed registry technology would grow from $\$ 2.5$ billion in 2017 to $\$ 2$ trillion in 2030 .

Intellectual property management. A significant role in international trade is played by the sale of digital goods: music, movies, software. All of these products require intellectual property protection because their circulation cannot be restricted without the use of special technologies due to the intangible form of these products. Such technologies are offered by blockchain, which allows for better administration and ensures the transfer of rights to different jurisdictions. Blockchain can affect both the management of digital assets and the development of the industry. The use of such technologies allows the formation of first use proofing, the rights registration, and the settlement of payments for the using a product. For example, blockchain can simplify the transfer of photos, drawings, art, and literature. This technology makes it possible to catalog a product and make it possible to identify it and determine ownership quickly. Thus, the creators of a product can avoid registering it by traditional means since blockchain will be able to do this work without legal procedure, staff involvement, and data processing. The technology will make it impossible to duplicate data, and it will also make it possible to find fakes and trace them quickly. When it comes to non-digital goods, blockchain will provide proof of its existence but not of its use. It will not guarantee that the 
person registering the product is indeed the original author of the work. A non-digital product can be added to the database with a digital fingerprint.

When it comes to trademarks, using blockchain, it is possible to prove the first use or registration of a mark. Blockchain also has the ability to facilitate the registration of patents. With the use of one system, all organizations in the world could find analogs of such patents and verify their innovativeness and belonging to certain persons. Finally, blockchain allows the introduction of the concept of international copyright protection, as currently, this process is only regulated at the territorial level.

Organization of government procurement. Government procurement is one of the main components of international trade. Such purchases, as a rule, form $10-15 \%$ of GDP. According to the calculation of experts, the turnover of public procurement is $\$ 9.5$ trillion. Public procurement experts estimate that about $20-25 \%$ of all procurements involve fraud or corruption (OECD, 2016). Moreover, if we save just $10 \%$ on public procurement, many EU countries will end up with a surplus rather than a deficit budget (European Commission, 2004). So the issue of transparency in the organization of procurement is very acute for many states. At the very least, blockchain can offer a highly efficient electronic environment in which all data will remain unchanged for years to come. Second, blockchain can provide the security for such transactions with smart contracts and the tracking of the entire procurement process, from the submission of advertisements and the search for the most effective bids to the control procedures for delivering the necessary products. But the most important thing about blockchain in public procurement is that it makes the process transparent and public. Today, many countries are trying to switch to these technologies in public procurement; in particular, the first ones are developed countries: the USA and Canada. Today, the initiative to connect public procurement to the blockchain was put forward by the Arab Emirates and Mexico.

It should be noted that blockchain technology activation today contributes to the rapid development of the economy. According to experts, by 2030, additional revenues from the use of blockchain are estimated at 3.1 trillion dollars (Fig. 8).

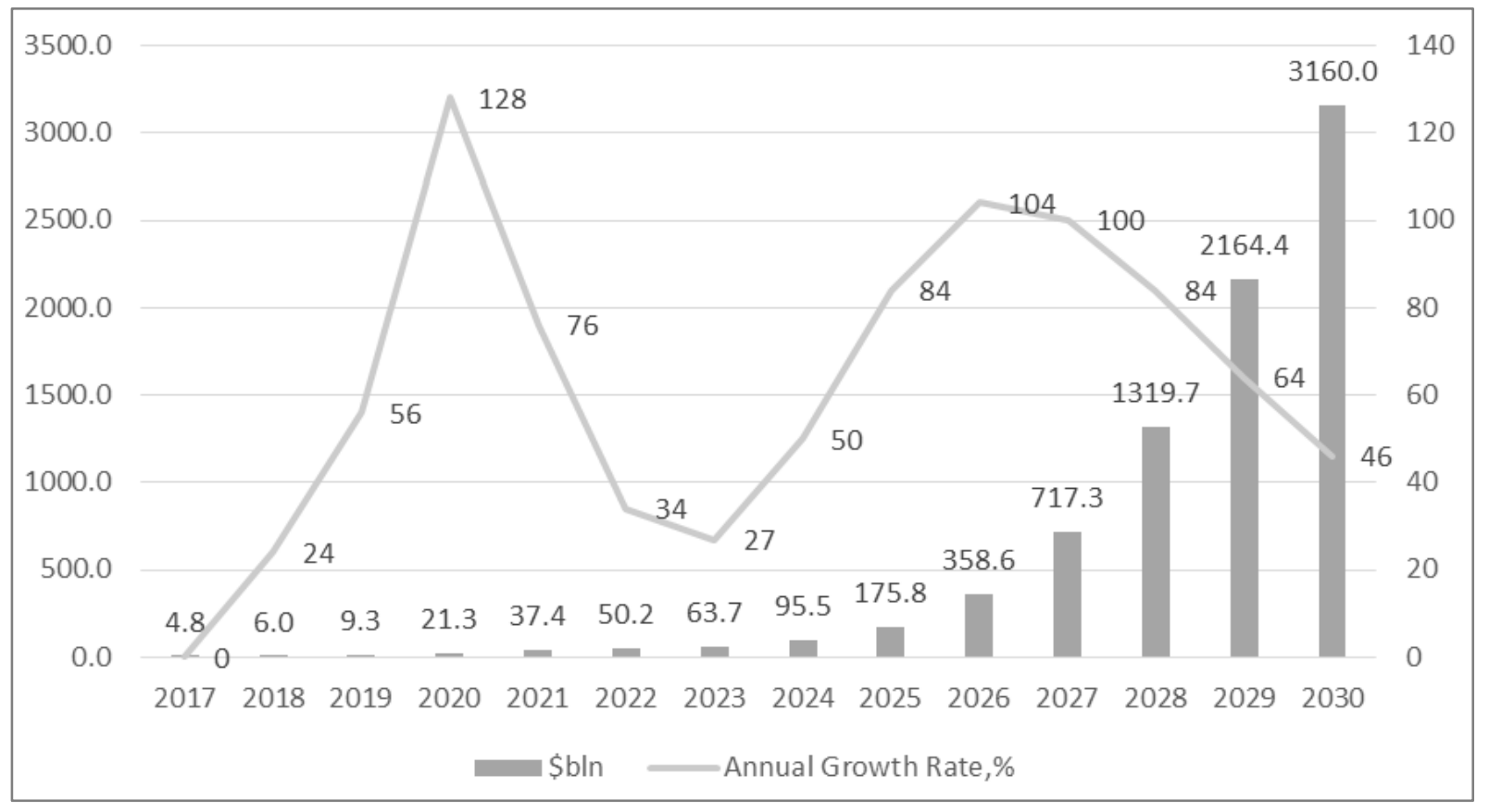

Source: Kandaswamy \& Furlonger, 2018

Figure 8. Adding value to the global economy using blockchain, $\$$ billion 
In order to determine the share of international trade in GDP, we use the data in Fig. 5. to obtain a five-year average. The average share of international trade in GDP is:

$$
(27,62+27,31+28,97+27,17+26,09) / 5=27,43 \% .
$$

Based on the fact that international trade accounts for about $27.4 \%$ of total GDP, we can predict the trend of international trade adding value using blockchain technology. Moreover, the Pearson coefficient between GDP and the volume of international trade (including financial business) is 0.82 , which allows us to assume sufficiently high prediction reliability.

Thus, with the use of blockchain, international trade could increase by $\$ 14$ billion, and by 2030 it could reach $\$ 866$ billion (Figure 9).

However, according to Gartner, blockchain is in an active growth phase, after which investment activity will decline, and the technology will refocus on creating business models for operating companies, regardless of their industry. By 2030, there will be the third phase of development, which will be the implementation of this technology in economic processes.

Table 1. The added value calculation of international trade using blockchain, $\$$ billions

\begin{tabular}{|c|c|c|c|c|c|c|c|c|c|c|c|c|c|c|}
\hline Year & $\mathbf{2 0 1 7}$ & $\mathbf{2 0 1 8}$ & $\mathbf{2 0 1 9}$ & $\mathbf{2 0 2 0}$ & $\mathbf{2 0 2 1}$ & $\mathbf{2 0 2 2}$ & $\mathbf{2 0 2 3}$ & $\mathbf{2 0 2 4}$ & $\mathbf{2 0 2 5}$ & $\mathbf{2 0 2 6}$ & $\mathbf{2 0 2 7}$ & $\mathbf{2 0 2 8}$ & $\mathbf{2 0 2 9}$ & $\mathbf{2 0 3 0}$ \\
\hline $\begin{array}{c}\text { Adding value to the } \\
\text { global economy using } \\
\text { blockchain }\end{array}$ & 4,8 & 6,0 & 9,3 & 21,3 & 37,4 & 50,2 & 63,7 & 95,5 & 175,8 & 358,6 & 717,3 & 1319,7 & 2164,4 & 3160,0 \\
\hline $\begin{array}{c}27.4 \% \text { of adding value } \\
\text { to the global economy } \\
\text { using blockchain }\end{array}$ & 1 & 2 & 3 & 6 & 10 & 14 & 17 & 26 & 48 & 98 & 197 & 362 & 593 & 866 \\
\hline
\end{tabular}

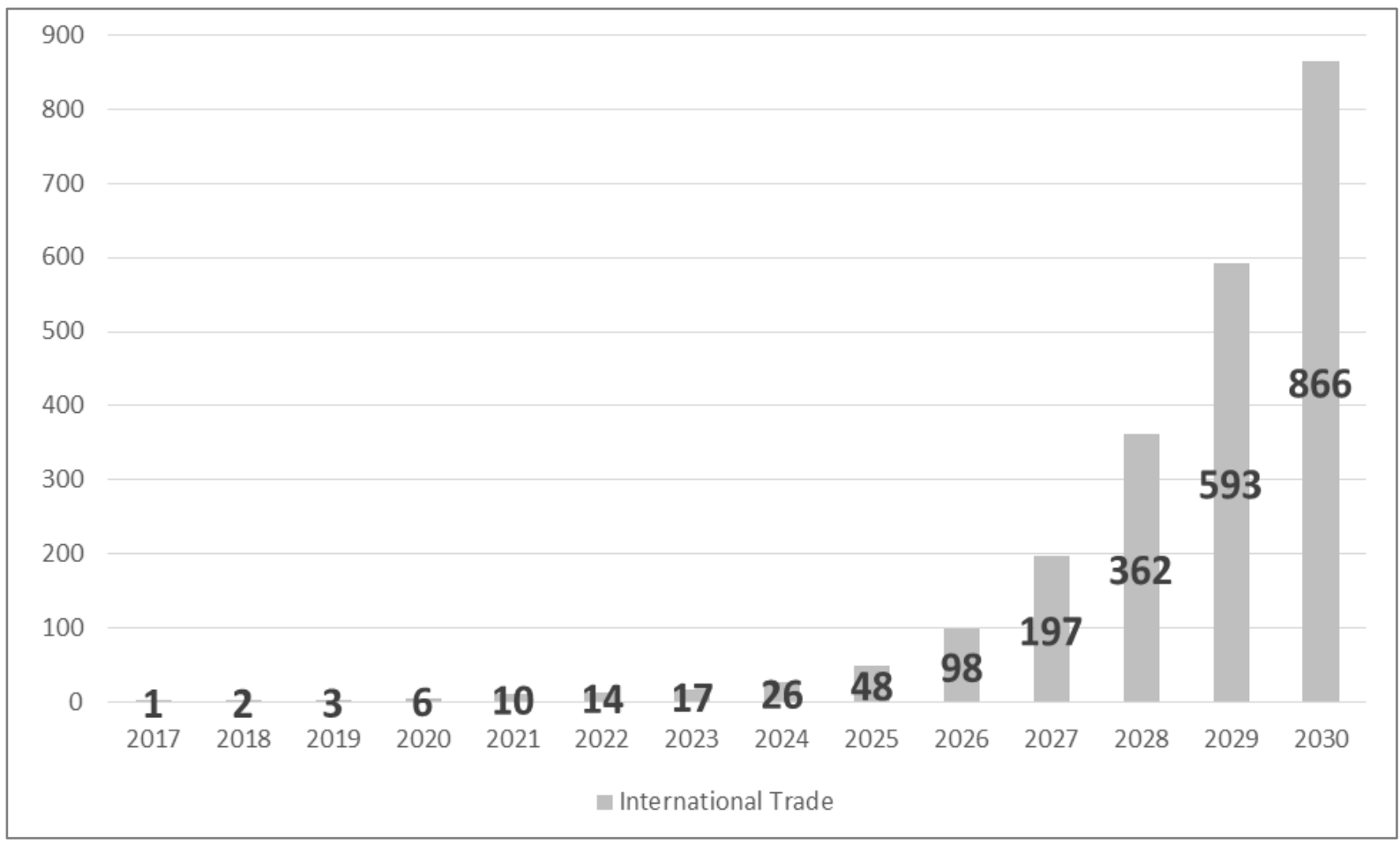

Source: Author's calculations

Figure 9. The added value of international trade using blockchain, $\$$ billions 


\section{Discussion}

The issue of the effective application of blockchain in different sectors of the economy is well enough researched. Specifically, more than 20,000 studies on the topic can be found in the Scopus catalog (2021), with research peaking in 2019-2020. Today, however, blockchain research has moved beyond cryptocurrencies. Most scientists and technology transfer specialists see the prospects for building socioeconomic processes and even a fully robotic economy (Arduengo \& Sentis, 2021) using blockchain. In particular, blockchain is a way to improve the efficiency of supply chains (Budak \& Coban, 2021 ); it is the primary tool for the widespread use of smart contracts (Nanayakkara et al., 2021) and generally allows the advancement of digital goods and services industry: for example, the global production of movies, music, software that face great problems with pirated use (Patrickson et al., 2021). It is safe to say that almost every sector of the economy can apply these technologies, which will reduce costs and increase the level of security and control over transactions. According to Andoni et al. (2019), it is advisable to apply the technology in the energy sector, which will be able to increase the level of security and establish accurate supply chains. Of course, the technology will further extend to e-commerce ( $\mathrm{Li}$ et al.,2020) and financial business, particularly banking payments (Damico, 2020). Over time, blockchain will expand beyond the commercial sector. It could improve public administration (Olnes et al.,2017), particularly the technology will be used to store medical data (Zhang \& Boulos,2020) and in education (Ray et al.,2020) and other industries.

\section{Conclusions}

Thus, blockchain technology has great potential in the development of international trade. By 2030, using these technologies, international trade could increase by $\$ 866$ billion. It will be due to:

- improvements in international trade settlements that conduct instant payments for goods or services shipped with guaranteed payment security, resulting in increased trade turnover;

- application of smart contracts, which improve control and quality of services and also accelerate export-import operations;

- improving the logistics chain by reducing paperwork and losses due to illegal or gray shipments;

- reducing the cost of intermediary services by reducing banking services by $11 \%$;

- developing trade in intellectual goods, which will be protected from pirate use and thereby increase the level of sales; organization of public procurement, through which it will be possible to remove $20 \%$ of all purchases from corrupt schemes.

These technologies can be implemented in all sectors of the economy, with the most positive effects being felt in the financial sector and in the digital goods trade sector. Other sectors of the economy will also be able to improve their efficiency, creating an additional $\$ 3.1$ trillion GDP value.

The practical significance of the study lies in the monetary evaluation of blockchain technology applications in international trade. While using these statistical materials, there is an opportunity to assess the potential use of blockchain in any industry. In the future, the topic will be developed at the global level in order to build models of effective management of the economies of different countries.

\section{REFERENCES}

[1] 51 Critical Blockchain Statistics: 2021 Data Analysis \& Market Share. (2021). Finances Online. UR1: https://financesonline.com/blockchain-statistics/

[2] A Report on the Functioning of Public Procurement Markets in the EU: Benefits from the Application of EU Directives and Challenges for the Future. (2004). European Commission. Brussels: European Commission.

[3] Andoni, M., Robu, V., Flynn, D., Abram, S., Geach, D., Jenkins, D., McCallum, P., Peacock, F. (2019). Blockchain technology in the energy sector: A systematic review of challenges and opportunities. Renewable Sustainable Energy Review, vol. 100, 143-174. DOI: https://doi.org/10.1016/j.rser.2018.10.014

[4] Arduengo, M., Sentis, L. (2021). The Robot Economy: Here It Comes. International Journal of Social Robotics, 13(5), 937-947. DOI: 10.1007/s12369-020-00686-1

[5] Blockchain use in banking and financial services market size worldwide in 2018 and 2019 with a forecast to 2026 . (2021). Statista. URL: https://www.statista.com/statistics/1 229290/blockchain-in-banking-and-financial-services-mar ket-size/

[6] Budak, A., Çoban, V. (2021). Evaluation of the impact of blockchain technology on supply chain using cognitive maps. Expert Systems with Applications, 184. https://doi.org/10.1016/j.eswa.2021.115455

[7] Can Blockchain revolutionize international trade? (2021). WTO. URL:https://www.wto.org/english/res e/publication s_e/blockchainrev18_e.htm

[8] Chang, Y., Iakovou, E. and Shi, W. (2019). Blockchain in global supply chains and cross border trade: a critical synthesis of the state-of-the-art, challenges and opportunities. International Journal of Production Research, 58,7. DOI: https://doi.org/10.1080/00207543.20 19.1651946 
[9] Damico, F. (2020). How technology is reshaping financial services:Blockchain use cases in the banking industry,Ph.D. dissertation, Politecnico di Torino, Turin, Italy.

[10] Derindag, O., Yarygina, I., Tsarev, Yu. (2020). International trade and blockchain technologies: implications for practice and policy. IOP Conf. Series: Earth and Environmental Science, 421. DOI: $10.1088 / 1755-1315 / 421 / 2 / 022051$

[11] How can blockchain improve supply chains? (2021). VC. URL:

https://vc.ru/crypto/51121-kak-blokcheyn-mozhet-usovers henstvovat-cepochki-postavok

[12] Kandaswamy, R., Furlonger, D. (2018). Blockchain-Based Transformation: A Gartner Trend Insight Report. Gartner. URL:

https://www.gartner.com/en/doc/3869696-blockchain-base d-transformation-a-gartner-trend-insight-report

[13] Li, M., Shao, S., Ye, Q., Xu, G., Huang, G.(2020). Blockchain-enabled logistics finance execution platform for capital-constrained E-commerce retail. Robotics and Computer-Integrated Manufacturing, vol. 65. DOI: https://doi.org/10.1016/j.rcim.2020.101962

[14] Mamchur, L., Nedybaliuk, O. (2018). Civil law realities of admissibility of using a smart contract in contractual relations. Historical and Legal Journal, 2 (12), 90-94

[15] Nanayakkara, S., Perera, S., Senaratne, S., Weerasuriya, G.T., Bandara, H.M.N.D. (2021). Blockchain and smart contracts: A solution for payment issues in construction supply chains. Informatics $8 \quad$ (2),36. DOI: https://www.mdpi.com/2227-9709/8/2/36

[16] Olnes, S., Ubacht, J., Janssen, M. (2017). Blockchain in government: Benefits and implications of distributed ledger technology for information sharing. Government Inf. Quart., vol. 34 , no. $3,355-364$.

[17] Patrickson, B. (2021). What do blockchain technologies imply for digital creative industries?. Creativity and Innovation Management, 30(3), 585-595. DOI: https://doi.org/10.1111/caim.12456

[18] Preventing Corruption in Public Procurement (2016). Organisation for Economic Development and Co-operation (OECD), Paris: OECD.

[19] Ray, P., Dash, D., Salah, K., Kumar, N. (2020). Blockchain for IoT-based healthcare: Background, consensus, platforms, and use cases. IEEE Syst. J. DOI: 10.1109/JSYST.2020.2963840.

[20] Search results (2021). SCOPUS. URL:https://scopus.com

[21] Sirimanne, S., Freire, C. (2021). How blockchain can power sustainable development. UNICTAD. URL: https:/unctad. org/news/how-blockchain-can-power-sustainable-develop ment

[22] Smith, S. (2021). Blockchain Deployments to Save Banks More Than $\$ 27 b n$ Annually by 2030. JUNIPER. URL: https://www.juniperresearch.com/press/blockchain-deploy ments-save-banks-27bn-by-2030

[23] The blockchain will save banks up to $\$ 27$ billion a year. (2021). Bloomchain. URL: https://bloomchain.ru/detailed/ blokchejn-pozvolit-bankam-ekonomit-do-27-mlrd-v-god

[24] World Trade Statistical Review (2021). World Trade Organization. URL: https://www.wto.org/english/res_e/st atis_e/wts2021_e/wts2021_e.pdf

[25] Zhai, H., Tan, R. (2021). The Impact of Blockchain Technology on International Trade and International Settlement. ACM International Conference Proceeding Series, 3465637. DOI: https://doi.org/10.1145/3465631.34 65637

[26] Zhang, P., Boulos, N.(2020). Blockchain solutions for healthcare, in Precision Medicine for Investigators, Practitioners and Providers. New York, NY, USA: Academic. 